\title{
Low levels of maximal aerobic power impair the profile of mood state in individuals with temporal lobe epilepsy
}

\author{
Os baixos níveis de potência aeróbia máxima prejudicam o perfil do estado de humor em \\ indivíduos com epilepsia do lobo temporal
}

Rodrigo Luiz Vancini ${ }^{1}$, Claudio Andre Barbosa de Lira ${ }^{2}$, Marilia dos Santos Andrade ${ }^{3}$, Cristiano de Lima ${ }^{4}$, Ricardo Mario Arida ${ }^{3}$

\begin{abstract}
Objective: To investigate the correlation between cardiorespiratory fitness and mood state in individuals with temporal lobe epilepsy (TLE). Method: Individuals with TLE $(n=20)$ and healthy control subjects $(C, n=20)$ were evaluated. Self-rating questionnaires were used to assess mood (POMS) and habitual physical activity (BAECKE). Cardiorespiratory fitness was evaluated by a maximal incremental test. Results: People with TLE presented lower cardiorespiratory fitness; higher levels of mood disorders; and lower levels of vigor when compared to control health subjects. A significant negative correlation was observed between the levels of tension-anxiety and maximal aerobic power. Conclusion: Low levels of cardiorespiratory fitness may modify the health status of individuals with TLE and it may be considered a risk factor for the development of mood disorders.
\end{abstract}

Keywords: epilepsy, profile of mood state, POMS, physical activity, exercise, cardiorespiratory fitness.

\section{RESUMO}

Objetivo: Investigar a correlação entre aptidão cardiorrespiratória e variáveis de estado de humor em indivíduos com epilepsia do lobo temporal (ELT). Método: Indivíduos com ELT $(n=20)$ e controles saudáveis $(C, n=20)$ foram avaliados. Administraram-se questionários para avaliar o estado de humor (POMS) e nível de atividade física habitual (BAECKE). Avaliou-se a aptidão cardiorrespiratória por teste incremental máximo. Resultados: Pessoas com ELT apresentaram menor aptidão cardiorrespiratória; elevados niveis de transtornos do humor; e menor nível de vigor, quando comparadas ao grupo C. Observou-se correlação negativa significativa entre os níveis de tensãoansiedade e a potência aeróbica máxima. Conclusão: O baixo nível de aptidão cardiorrespiratória pode modificar o estado de saúde de indivíduos com ELT e pode ser considerado fator de risco para o desenvolvimento de transtornos de humor.

Palavras-chave: epilepsia, perfil do estado de humor, POMS, atividade física, exercício, aptidão cardiorrespiratória.

Epilepsy is a chronic neurological disorder that leads to a sedentary lifestyle, low physical fitness, and numerous comorbidities ${ }^{1}$. Mood disturbances, particularly depression and anxiety, are co-morbidities that have a high incidence in people with epilepsy ${ }^{2,3}$. Traditionally, pharmacological therapy remains the mainstay of treatment for mood disturbances $^{2}$. However, non-pharmacological treatments such as physical activity have also been used to reduce mood disturbance levels. In the general population, regular exercise contributes to mood-related benefits ${ }^{4}$ and minimizes the impact of stressful life events ${ }^{5}$; similar results have been found in people with epilepsy ${ }^{6,7}$.

The favorable effects of regular exercise on physical fitness and general health are unquestionable and numerous studies have reported positive effects of regular physical activity in people with epilepsy ${ }^{6,7,8,9,10,11,12}$. Regular physical

${ }^{1}$ Centro de Educação Física e Desportos, Universidade Federal do Espírito Santo, Vitória ES, Brazil;

${ }^{2}$ Setor de Fisiologia Humana e do Exercício, Faculdade de Educação Física e Dança, Universidade Federal de Goiás, Goiânia Go, Brazil;

${ }^{3}$ Departamento de Fisiologia, Universidade Federal de São Paulo, Sao Paulo SP, Brazil;

${ }^{4}$ Departamento de Psicobiologia, Universidade Federal de São Paulo, Sao Paulo SP, Brazil.

Correspondence: Ricardo Mario Arida; Departamento de Fisiologia, Universidade Federal de São Paulo; Rua Botucatu, 862 / $5^{\circ}$ andar / Ed. Ciências Biomédicas, Vila Clementino; 04023-900 São Paulo SP, Brasil; E-mail: arida.nexp@epm.br

Conflict of interest: There is no conflict of interest to declare.

Support: This study was supported by Conselho Nacional de Desenvolvimento Científico e Tecnológico (CNPq), Fundacão de Amparo à Pesquisa do Estado de São Paulo (FAPESP), Instituto Nacional de Neurociência Translacional (INNT) (Brazil) and FAPESP-MCT/CNPq-PRONEX. 
activity has been proposed as a positive coping strategy in the management of patients with epilepsy that are diagnosed with mood disorders ${ }^{13,14}$. Roth et al. ${ }^{15}$ reported that individuals with epilepsy are more predisposed to mood disorders and that exercise might minimize this predisposition. Recently, de Lima et al. ${ }^{16}$ reported that the level of physical activity in leisure time can predict mood state disorders in epilepsy. Indeed, the effects of physical exercise on people with epilepsy such as an improvement in psychological health and a decrease in seizure frequency have been increasingly reported in the literature ${ }^{11,12,17}$. We have previously proposed that physical exercise minimizes mood disorders, particularly depression, in epilepsy ${ }^{12}$. In this regard, the relationship between physical activity levels and mood disorders may be mediated in part by physiological changes, such as lower levels of maximal aerobic power ${ }^{18,19}$. Therefore, the aim of the present study was to verify the possible association between cardiorespiratory fitness, habitual physical activity level, and mood state variables in individuals with temporal lobe epilepsy.

\section{METHOD}

\section{Participants}

Patients with epilepsy were recruited from a Neurological Clinic (Clínica Itapeti, Mogi das Cruzes, Brazil). The epilepsy group consisted of 20 individuals with temporal lobe epilepsy (TLE) and the control group (C) consisted of healthy subjects (recruited from members of the Federal University of Sao Paulo), matched for gender and age with the TLE group. Subjects were informed of the purpose of the study prior to their participation. The TLE and C groups consisted of 11 women and 9 men $(n=20)$. General characteristics (physical and physical fitness characteristics) of the TLE and C groups are presented in Table 1. The exclusion criteria were any progressive neurological disorders (with the exception of epilepsy) and cognitive limitations. Inclusion criteria were subjects with TLE for at least 2 years and medication compliance. The study was approved by the Federal University of Sao Paulo's Research Ethics Committee (no.
1845/06) and all participants voluntarily signed informed consent form prior to participating in the study. For individuals younger than 18 years, the participants' parents signed the informed consent form.

\section{Study design}

Participants from both groups were submitted to the following phases in this order: (1) anamnesis, physical examination, electrocardiogram at rest and during effort, (2) cardiopulmonary exercise test (CPET), and (3) answered the following questionnaires: (a) Profile of Mood States (POMS) and (b) level of habitual physical activity (BAECKE) questionnaire.

\section{Questionnaires \\ Habitual physical activity questionnaire}

The habitual level of physical activity in the C and TLE groups was evaluated by the Baecke questionnaire ${ }^{20}$. This questionnaire consists of 16 questions involving three habitual physical activity scores (occupational physical activity, physical exercise in leisure time, and leisure and locomotion activities) relating to the previous 12 months. The total score for habitual physical activity was obtained by adding together the cited three habitual physical activity scores. The total scores were recorded for the statistical analysis.

\section{Profile of Mood States Evaluation}

The mood profile in the C and TLE groups was assessed by the POMS questionnaire, which is a self-reporting questionnaire consisting of 65 items that fit into 6 categories: tension-anxiety, depression, anger-hostility, vigor, fatigue and confusion, and scored from 1-4 according to severity. The questionnaire yields a global measure of mood. The global score is computed by subtracting the positive category (vigor) from the sum of the five negative categories (tension, depression, anger, fatigue and confusion). The standard instructional set of the POMS questionnaire was employed in this study. The POMS questionnaire was utilized because of its reliability, validity, feasibility and common use in psychometric studies ${ }^{21,22}$.

Table 1. Characteristics of C and TLE groups.

\begin{tabular}{lccc}
\hline & C & TLE & p-value \\
\hline $\mathrm{N}$ & 20 & 20 & $\mathrm{~N} / \mathrm{A}$ \\
Age $(\mathrm{yr})$ & $34.6 \pm 11.4$ & $34.1 \pm 12.2$ & 0.8604 \\
Height $(\mathrm{cm})$ & $167.7 \pm 11.3$ & $168.4 \pm 11.0$ & 0.6849 \\
Body mass $(\mathrm{kg})$ & $69.2 \pm 17.3$ & $72.2 \pm 17.5$ & 0.871 \\
Body mass index $\left(\mathrm{kg} / \mathrm{m}^{2}\right)$ & $24.3 \pm 3.5$ & $25.3 \pm 5.1$ & 0.636 \\
Physical activity total score (Baecke questionnaire) & $7.6 \pm 1.3$ & $7.1 \pm 1.2$ & 0.2852 \\
Maximal aerobic power $(\mathrm{ml} / \mathrm{kg} / \mathrm{min})$ & $34.4 \pm 8.1$ & $28.8 \pm 6.7^{*}$ & 0.0361 \\
\hline
\end{tabular}

Data are expressed as mean \pm SD. ${ }^{*}$ Statistically significant difference in relation to C (Mann Whitney test, $p \leq 0.05$ ). N/A: Not applicable; C: Control; TLE: Temporal lobe epilepsy. 


\section{Cardiopulmonary exercise test (CPET)}

A graded maximal exercise test was administered to the $\mathrm{C}$ and TLE groups to determine the maximal oxygen uptake $(\mathrm{ml} / \mathrm{kg} / \mathrm{min})$. Maximal oxygen uptake is a variable used to assess maximal aerobic power in healthy people and in people with epilepsy ${ }^{23}$. The subjects were given a standardized set of instructions to explain the test. After these preliminary procedures, each subject was submitted to an incremental maximal exercise test on an air-brake ergometer (Schwinn Airdyne ${ }^{\circledR}$ Exercise Bike, Nautilus Inc, USA). The schedule of this test consisted of a 5-min warm-up at between 10 and 25 watts, followed by progressive load increases at a rate of 10 to 25 watts every two minutes, according to the subject's cardiorespiratory fitness, until subject exhaustion. Maximal oxygen uptake was always defined as the highest 20-s averaged oxygen uptake value with inclusion criteria consistent with conventional guidelines for maximal oxygen uptake (e.g., an inability to sustain workload, relative HR $>95 \%$ age predicted, or respiratory exchange ratio at maximal exercise $>1.1$ ). During the exercise test, subjects were verbally encouraged to exercise for as long as possible. Respiratory gas samples were analyzed breath-by-breath using a gas analyzer (Quark PFT, Cosmed ${ }^{\mathbb{R}}$, Italy). The gas analyzer was calibrated according to the manufacturer's specification prior to each test. Maximal oxygen uptake was recorded for the statistical analyses.

\section{Statistical analysis}

Normal distribution and homogeneity of the variances were verified using the Kolmogorov-Smirnov test. The difference between two measures was established by the Mann Whitney test (non-parametric test). To assess possible correlations between maximal aerobic power and total score for habitual physical activity with profile mood states domains we used the Spearman correlation test (alpha $\leq 0.05$ ). Results are presented as mean \pm standard deviation (SD). Results were statistically significant at $p \leq 0.05$. Statistical analyses were conducted using Graph Pad Prism software (San Diego, CA, USA).

\section{RESULTS}

Significant differences were found between the $\mathrm{C}$ and TLE groups in maximal oxygen uptake (Table 1). The TLE group presented lower maximal oxygen uptake $(28.8 \pm 6.7$ $\mathrm{ml} / \mathrm{kg} / \mathrm{min})$ compared with the C group $(34.4 \pm 8.1 \mathrm{ml} / \mathrm{kg} /$ $\min )(\mathrm{p}=0.0361)$. The Mann Whitney test revealed differences between the groups for different mood state domains. In the TLE group, the levels of tension-anxiety and confusion ( $48.2 \%, p=0.0223$ and $64.8 \%, p=0.0274$ respectively) were significantly higher compared to the $\mathrm{C}$ group. The level of vigor in the TLE group was $16.2 \%$ lower $(p=0.0223)$ compared to the $\mathrm{C}$ group. Furthermore, the mood disturbance total score was $83.7 \%$ higher in the TLE group $(p=0.0223)$ compared to the $\mathrm{C}$ group (Table 2). Spearman's correlation analysis (Table 3 ) showed a significant association between the tension-anxiety domain of the POMS questionnaire and maximal oxygen uptake $(\mathrm{p}=0.0460, \mathrm{r}=-0.31)$.

\section{DISCUSSION}

We examined the habitual physical activity levels, cardiorespiratory fitness, the level of mood disorders, and subsequently the impact (correlations) of physical fitness (physical activity levels and maximal aerobic power) on the prevalence of mood disorders in individuals with TLE. Our data showed that people with TLE presented lower levels of cardiorespiratory fitness than healthy subjects. In addition, when compared to healthy subjects, individuals with TLE presented higher levels of mood disorders (tension/anxiety and confusion) and lower levels of vigor/disposition. The present investigation also demonstrates a weak but significant correlation between the levels of tension/anxiety and maximal oxygen uptake, i.e. the lower the levels of cardiorespiratory fitness the higher the levels of tension/anxiety.

Mood and behavioral disturbances are common in epilepsy $y^{2,3,24}$ and have a negative effect on health status and quality of life ${ }^{3}$. It is important to note that regular physical

Table 2. Comparison of $C$ and TLE groups on the Profile of Mood States (POMS) scores domains.

\begin{tabular}{lcccc}
\hline & $C(n=20)$ & TLE $(n=20)$ & Effect size & p-value \\
\hline Tension-anxiety & $4.5 \pm 5.4$ & $8.7 \pm 5.5^{\star}$ & -0.36 & 0.0223 \\
Depression & $5.6 \pm 6.2$ & $10.6 \pm 13.0$ & -0.24 & 0.1938 \\
Anger-hostility & $6.3 \pm 6.8$ & $10.6 \pm 8.0$ & -0.28 & 0.0547 \\
Vigor & $19.7 \pm 5.4$ & $16.5 \pm 4.8^{\star}$ & 0.30 & 0.0482 \\
Fatigue & $6.1 \pm 5.1$ & $9.1 \pm 6.1$ & -0.25 & 0.0933 \\
Confusion & $1.3 \pm 4.6$ & $3.7 \pm 4.5^{\star}$ & -0.25 & 0.0274 \\
Disturbance mood total score & $4.2 \pm 24.6$ & $25.8 \pm 34.7^{*}$ & -0.33 & 0.0315
\end{tabular}

Data are expressed as mean \pm SD. *Statistically significant difference in relation to C (Mann Whitney test, p $\leq$ 0.05). POMS: Profile of mood state; C: Control; TLE: Temporal lobe epilepsy. 
Table 3. Spearman correlation coefficients (number of XY pairs $=40$ ) of the association between POMS scores domains and maximal aerobic power and physical activity total score (Baecke questionnaire).

\begin{tabular}{lcccc}
\hline POMS scores domains & r-value (maximal aerobic power) & p-value & r-value (physical activity total score) & $p$-value \\
\hline Tension-anxiety & -0.31 & $0.0460^{*}$ & -0.08 & 0.5911 \\
Depression & -0.18 & 0.2613 & 0.01 & 0.9335 \\
Anger-hostility & -0.31 & 0.0507 & -0.17 & 0.2729 \\
Vigor & 0.05 & 0.7627 & 0.27 & 0.0907 \\
Fatigue & -0.23 & 0.1411 & -0.13 & 0.4267 \\
Confusion & -0.09 & 0.5615 & 0.06 & 0.6875 \\
Disturbance mood total score & -0.24 & 0.1350 & -0.09 & 0.5807 \\
\hline
\end{tabular}

*Statistically significant correlation (Spearman coefficient, alpha $\leq 0.05$ ).

activity is a non-pharmacological therapy which can provide health benefits such as reduction in the risk of cardiovascular and endocrine diseases, improvement in bone and muscle conditioning ${ }^{25}$, and prevention of psychological and emotional disturbances ${ }^{10,15,17,26}$. Consistent with this, mood disturbances are more prevalent among sedentary rather than physically active individuals ${ }^{27}$. In this regard, Roth et al..$^{15}$ analyzed the effect of physical activity on depression levels in adults with epilepsy and found that active individuals were less depressed compared to sedentary individuals. Recently, de Lima et al. ${ }^{16}$ demonstrated that people with juvenile myoclonic epilepsy presented higher levels of mood disturbances when compared to healthy subjects. They showed that the level of physical activity in leisure time predicted $31 \%$ of depression levels and $26 \%$ of anxiety levels in epilepsy. These data suggest that low levels of physical activity may be considered a risk factor for the development of mood disorders and can play an important role in the global health status of individuals with epilepsy.

It has been reported in healthy subjects that lower levels of physical activity are associated with a greater presence of medical co-morbidities and social isolation ${ }^{26}$. In support of these findings, Vancini et al. ${ }^{23}$ demonstrated that individuals with TLE presented significantly lower levels of physical activity during leisure time (14.8\%) and lower and poorer emotional well-being (17.3\%) when compared to healthy subjects. These differences may be associated with the social isolation commonly observed in people with epilepsy ${ }^{28,29}$. Similarly, Nakken et al. ${ }^{9}$ observed that a 4-week exercise program improved the mental state and sociability of people with epilepsy. Furthermore, a regular exercise program improved performance and psychosocial quality of life of women with refractory epilepsy ${ }^{10}$. An improvement in the mood of individuals with epilepsy after 12 weeks of physical training has also been demonstrated by McAuley and collaborators ${ }^{17}$.

Given the positive contribution of physical activity towards epilepsy, it is reasonable to suggest that physical exercise intervention shows strong positive potential and may be used in an integrated approach in the complementary treatment of epilepsy ${ }^{12}$. In fact, efforts to promote knowledge about epilepsy and physical activity between health professionals are urgently needed to avoid prejudice in epilepsy treatment and to improve the quality of life and health status of epilepsy patients ${ }^{30}$. Since physical exercise can exert a positive impact on psychological state and seizure control $^{12}$, it is desirable that health professionals should recommend and encourage physical exercise programs for people with epilepsy. To this end, we propose that regular physical exercise can be a remarkably positive coping strategy in the treatment of psychological and mood disorders in people with epilepsy ${ }^{12,13}$. Finally, appropriate management by health professionals of mood states using physical activity can contribute to and positively influence the perceptions of this population of their quality of life and health status.

\section{Acknowledgements}

We would like to thank all of the subjects who volunteered their time to participate in this study.

\section{References}

1. Duncan JS, Sander JW, Sisodiya SM, Walker MC. Adult epilepsy. Lancet 2006;367:1087-1100.

2. Gaitatzis A, Trimble, MR, Sander JW. The psychiatric comorbidity of epilepsy. Acta Neurol 2004;11:207-220.

3. Thapar A, Kerr M, Harold G. Stress, anxiety, depression, and epilepsy: investigating the relationship between psychological factors and seizures. Epilepsy Behav 2009;14:134-140.

4. Petruzzello SJ, Landers DM, Hatfield BD, Kubitz KA, Salazar W. A meta-analysis on the anxiety-reducing effects of acute and chronic exercise. Sports Med 1991;11:143-182.
5. Brown JD, Siegel JM. Exercise as a buffer of life stress: a prospective study of adolescent health. Health Psychol 1988;7:341-353.

6. Arida RM, Scorza FA, Gomes da Silva S, Schachter SC, Cavalheiro EA. The potential role of physical exercise in the treatment of epilepsy. Epilepsy Behav 2010;17:432-435.

7. Arida RM, Peixinho-Pena LF, Scorza FA, Cavalheiro EA. Physical exercise: potential candidate as complementary therapy for epilepsy. Ann Indian Acad Neurol 2012;15:167.

8. Denio LS, Drake ME Jr, Pakalnis A. The effect of exercise on seizure frequency. J Med 1989;20:171-176. 
9. Nakken KO, Bjørholt PG, Johannesen SL, Loyning T, Lind E. Effect of physical training on aerobic capacity, seizure occurrence, and serum level of antiepileptic drugs in adults with epilepsy. Epilepsia 1990;31:88-94.

10. Eriksen HR, Bjørn E, Grønningsaeter $H$, Nakken KO, Løyning Y, Ursin $\mathrm{H}$. Physical exercise in women with intractable epilepsy. Epilepsia 1994;35:1256-1264.

11. Arida RM, Cavalheiro EA, da Silva AC, Scorza FA. Physical activity and epilepsy: proven and predicted benefits. Sports Med 2008;38:607-615.

12. Arida RM, Cavalheiro EA, Scorza FA. From depressive symptoms to depression in people with epilepsy: contribution of physical exercise to improve this picture. Epilepsy Res 2012;99:1-13.

13. Vancini RL, de Lira CA, Arida RM. Physical exercise as a coping strategy for people with epilepsy and depression. Epilepsy Behav 2013;29:431.

14. Vancini RL, de Lira CA, Arida RM. Physical exercise: potential candidate as coping strategy for people with epilepsy. Epilepsy Behav 2013;28:133

15. Roth DL, Goode KT, Williams VL, Faught E. Physical exercise, stressful life experience, and depression in adults with epilepsy. Epilepsia 1994;35:1248-1255.

16. de Lima C, de Lira CA, Arida RM, et al. Association between leisure time, physical activity, and mood disorder levels in individuals with epilepsy. Epilepsy Behav 2013;28:47-51.

17. McAuley JW, Long L, Heise J, et al. A Prospective evaluation of the effects of a 12-week outpatient exercise program on clinical and behavioral outcomes in patients with epilepsy. Epilepsy Behav 2001;2:592-600.

18. Cruickshank JM, Golrlin BJ, Jennet B. Air travel and thrombotic episodes: the economy class syndrome. Lancet 1988;340:497-498.

19. Convertino VA. Cardiovascular consequences of bed rest: effect on maximal oxygen uptake. Med Sci Sports Exerc 1997;29:191-196.
20. Baecke JA, Burema J, Frijters JE. A short questionnaire for the measurement of habitual physical activity in epidemiological studies. Am J Clin Nutr. 1982;36:936-942.

21. Morgan WP. Prediction of performance in athletics. In: Klavora P, Daniel JV, editors. Coach, athlete and the sport psychologist. Champaign, IL:Human Kinetics 1979:172-186.

22. Morgan WP, Costill DL, Flynn MG, Raglin JS, O’Connor PJ. Mood disturbance following increased training in swimmers. Med Sci Sports Exerc 1988;20:408-414.

23. Vancini RL, de Lira CA, Scorza FA, et al. Cardiorespiratory and electroencephalographic responses to exhaustive acute physical exercise in people with temporal lobe epilepsy. Epilepsy Behav 2010;19:504-508.

24. Noe KH, Locke DE, Sirven JI. Treatment of depression in patients with epilepsy. Curr Treat Options Neurol 2011;13:371-379.

25. Howley ET. Type of activity: resistance, aerobic and leisure versus occupational physical activity. Med Sci Sports Exerc 2001;33:364-369.

26. Vancampfort D, Correll CU, Probst M, et al. A review of physical activity correlates in patients with bipolar disorder. J Affect Disord 2013;145:285-291.

27. Berlin AA, Kop WJ, Deuster PA. Depressive mood symptoms and fatigue after exercise withdrawal: the potential role of decreased fitness. Psychosom Med 2006;68:224-230.

28. Bjørholt PG, Nakken KO, Røhme K, Hansen H. Leisure time habits and physical fitness in adults with epilepsy. Epilepsia 1990;31:83-87.

29. Arida RM, Scorza FA, Albuquerque M, Cysneiros RM, de Oliveira RJ, Cavalheiro EA. Evaluation of physical exercise habits in Brazilian patients with epilepsy. Epilepsy Behav 2003;4:507-510.

30. Vancini RL, Benedito-Silva AA, Sousa BS, et al. Knowledge about epilepsy among health professionals: a cross-sectional survey in Sao Paulo, Brazil. BMJ Open 2012;2:000919. 